\title{
Autoimmune thyroid disease: a novel risk factor for atherosclerosis?
}

\author{
Donald S. A. McLeod
}

Received: 20 March 2013/Accepted: 4 April 2013/Published online: 12 April 2013

(C) Springer Science+Business Media New York 2013

Atherosclerosis is the world's leading cause of death [1]. Much, but not all, is known about atherosclerosis development. Classical modifiable risk factors include diabetes mellitus, hypertension, hyperlipidemia, and smoking, while other important risk factors include abdominal obesity, excessive alcohol intake, lack of fruit and vegetable intake, and psychosocial factors [2].

The suggestion that thyroid function may be related to atherosclerosis is not new [3]. There is general agreement that overt hypothyroidism promotes cardiovascular disease, including atherosclerosis. Mechanisms through which decreased thyroid hormone concentrations lead to atherosclerosis include elevated low-density lipoprotein cholesterol, diastolic hypertension, heightened coagulability, and actions on vascular smooth muscle [3]. However, much debate continues whether subclinical hypothyroidism similarly leads to increased cardiovascular events. A very large meta-analysis of previous studies suggested modestly increased risk with subclinical hypothyroidism [4], although there was significant heterogeneity of the results among the studies included. The meta-analysis also found that by age, the youngest patients had the most positive hazard ratio estimate, but statistical significance was not reached, likely because of small subgroup numbers [4]. Interestingly, a recent paper reported increased cardiovascular events in younger ( $\leq 70$ years) but not older

D. S. A. McLeod (

Cancer Control Group, Queensland Institute of Medical

Research, Herston, QLD 4029, Australia

e-mail: donald.mcleod@qimr.edu.au

D. S. A. McLeod

Departments of Internal Medicine and Aged Care, and Endocrinology, Royal Brisbane and Women's Hospital, Herston, QLD, Australia
( $>70$ years) patients with subclinical hypothyroidism [5]. This is interesting because subclinical hypothyroidism in some older individuals may not be pathologic, and is less likely to be due to autoimmune thyroid disease [6].

Some authors hypothesize that autoimmune thyroid disease per se may play a role in atherosclerosis development. Biochemically, it has been reported that Hashimoto's thyroiditis causing subclinical hypothyroidism is associated with low-grade inflammation as measured by high-sensitivity C-reactive protein and interleukin-6 levels, and is linked to endothelial dysfunction [7]. That systemic lowgrade inflammation has been demonstrated in Hashimoto's thyroiditis is not surprising given that peripheral (as opposed to simply intra-thyroidal) activation of the immune system in Hashimoto's thyroiditis patients has also been reported [8]. At the organ level, another report showed that arterial stiffness, but not carotid intima-medial thickness (CIMT), was increased in euthyroid Hashimoto's thyroiditis patients compared to controls [9]. Ciccone et al. [10] investigated overweight and obese euthyroid patients, finding that CIMT was indeed increased in patients with Hashimoto's thyroiditis, compared to those without. At the population level, in a retrospective study, Nyirenda et al. [11] found that Scottish patients with Hashimoto's thyroiditis over (but not under) the age of 50 years had more hospitalizations for cardiovascular disease than controls. Furthermore, using nationwide Swedish linked data registries, Zoller et al. [12] recently reported that patients hospitalized with Hashimoto's thyroiditis (and numerous other autoimmune disorders) subsequently had higher rates of coronary heart disease and stroke [13].

In this issue of Endocrine, Topaloglu et al. [14] add further evidence to the debate. This study recruited 48 euthyroid premenopaual women with Hashimoto's thyroiditis and compared them to 18 controls with respect to 
CIMT, cardiovascular risk factors, and metabolic parameters. The authors found that Hashimoto's thyroiditis patients displayed greater CIMT than controls, and that Hashimoto's thyroiditis patients had higher body mass index, although body mass index did not independently impact on CIMT in linear regression analysis.

The work is an interesting "proof of concept" study, and should prompt further investigation. However, some words of caution are required. The study is small with relatively few controls that might not be truly representative of the wider community, and chance could account for the findings. This is important given that CIMT was not associated with euthyroid Hashimoto's thyroiditis in another small study [9]. Similarly, inadvertent selection bias could account for the characteristics of the Hashimoto's thyroiditis patients. If overweight but euthyroid women sought evaluation for thyroid disorders more frequently than those of normal body weight, the result would be a higher proportion of overweight women attending the Endocrinology clinic. Under this scenario, the Hashimoto's thyroiditis group could have higher metabolic risk unrelated to their autoimmune thyroid disease. We should be particularly aware of this possibility given another small study did not find a relationship between Hashimoto's thyroiditis and body weight in their overall cohort of euthyroid Hashimoto's thyroiditis, although in that study euthyroid Hashimoto's thyroiditis patients did have slightly higher lowdensity lipoprotein cholesterol concentrations than controls [15]. The small sample size also hampers full evaluation of the relationships between known cardiovascular risk factors, Hashimoto's thyroiditis, and CIMT. Finally, the subjects had low overall cardiovascular risk and CIMT was well within normal limits; it is not clear that any potential relationship between CIMT and Hashimoto's thyroiditis can be generalized to other patient groups, or that the statistically significant increase in CIMT seen in Hashimoto's thyroiditis patients would lead to actual increased cardiovascular events.

Further studies with biochemical and imaging surrogates of cardiovascular disease will be useful to inform potential mechanisms of autoimmune thyroid disease influencing atherosclerosis development. Final proof of a role for autoimmune thyroid disease in atherosclerosis would require large, well-designed, prospective studies assessing specific cardiovascular endpoints. These confirmatory studies should address whether abnormal thyroid function or autoimmunity itself was important, and would also need to account for how autoimmune thyroid disease influenced known causal pathways for atherosclerosis, given that current risk factors account for a high proportion of cardiovascular disease [2].

If most cardiovascular events are attributable to known risk factors, does it matter whether there is also an association with autoimmune thyroid disease? The answer is yes. A causal relationship between autoimmune thyroid disease and atherosclerosis (even if mediated through traditional risk factors) would likely be an indication for therapy to prevent autoimmune thyroid disease. At least one potential agent has been identified and undergone promising initial animal studies [16]. It is, therefore, imperative that future high-quality evidence confirms or refutes that autoimmune thyroid disease is a risk factor for atherosclerosis. The current report by Topaloglu et al. [14] reinforces this need.

Acknowledgments A Cancer Council Queensland $\mathrm{PhD}$ scholarship supports D.M.

Conflict of interest There are no conflicts of interest to declare.

\section{References}

1. R. Lozano, M. Naghavi, K. Foreman, S. Lim, K. Shibuya, V. Aboyans, J. Abraham, T. Adair, R. Aggarwal, S.Y. Ahn, M. Alvarado, H.R. Anderson, L.M. Anderson, K.G. Andrews, C. Atkinson, L.M. Baddour, S. Barker-Collo, D.H. Bartels, M.L. Bell, E.J. Benjamin, D. Bennett, K. Bhalla, B. Bikbov, A. Bin Abdulhak, G. Birbeck, F. Blyth, I. Bolliger, S. Boufous, C. Bucello, M. Burch, P. Burney, J. Carapetis, H. Chen, D. Chou, S.S. Chugh, L.E. Coffeng, S.D. Colan, S. Colquhoun, K.E. Colson, J. Condon, M.D. Connor, L.T. Cooper, M. Corriere, M. Cortinovis, K.C. de Vaccaro, W. Couser, B.C. Cowie, M.H. Criqui, M. Cross, K.C. Dabhadkar, N. Dahodwala, D. De Leo, L. Degenhardt, A. Delossantos, J. Denenberg, D.C. Des Jarlais, S.D. Dharmaratne, E.R. Dorsey, T. Driscoll, H. Duber, B. Ebel, P.J. Erwin, P. Espindola, M. Ezzati, V. Feigin, A.D. Flaxman, M.H. Forouzanfar, F.G. Fowkes, R. Franklin, M. Fransen, M.K. Freeman, S.E. Gabriel, E. Gakidou, F. Gaspari, R.F. Gillum, D. GonzalezMedina, Y.A. Halasa, D. Haring, J.E. Harrison, R. Havmoeller, R.J. Hay, B. Hoen, P.J. Hotez, D. Hoy, K.H. Jacobsen, S.L. James, R. Jasrasaria, S. Jayaraman, N. Johns, G. Karthikeyan, N. Kassebaum, A. Keren, J.P. Khoo, L.M. Knowlton, O. Kobusingye, A. Koranteng, R. Krishnamurthi, M. Lipnick, S.E. Lipshultz, S.L. Ohno, J. Mabweijano, M.F. MacIntyre, L. Mallinger, L. March, G.B. Marks, R. Marks, A. Matsumori, R. Matzopoulos, B.M. Mayosi, J.H. McAnulty, M.M. McDermott, J. McGrath, G.A. Mensah, T.R. Merriman, C. Michaud, M. Miller, T.R. Miller, C. Mock, A.O. Mocumbi, A.A. Mokdad, A. Moran, K. Mulholland, M.N. Nair, L. Naldi, K.M. Narayan, K. Nasseri, P. Norman, M. O'Donnell, S.B. Omer, K. Ortblad, R. Osborne, D. Ozgediz, B. Pahari, J.D. Pandian, A.P. Rivero, R.P. Padilla, F. Perez-Ruiz, N. Perico, D. Phillips, K. Pierce, C.A. Pope 3rd, E. Porrini, F. Pourmalek, M. Raju, D. Ranganathan, J.T. Rehm, D.B. Rein, G. Remuzzi, F.P. Rivara, T. Roberts, F.R. De Leon, L.C. Rosenfeld, L. Rushton, R.L. Sacco, J.A. Salomon, U. Sampson, E. Sanman, D.C. Schwebel, M. Segui-Gomez, D.S. Shepard, D. Singh, J. Singleton, K. Sliwa, E. Smith, A. Steer, J.A. Taylor, B. Thomas, I.M. Tleyjeh, J.A. Towbin, T. Truelsen, E.A. Undurraga, N. Venketasubramanian, L. Vijayakumar, T. Vos, G.R. Wagner, M. Wang, W. Wang, K. Watt, M.A. Weinstock, R. Weintraub, J.D. Wilkinson, A.D. Woolf, S. Wulf, P.H. Yeh, P. Yip, A. Zabetian, Z.J. Zheng, A.D. Lopez, C.J. Murray, M.A. AlMazroa, Z.A. Memish, Global, regional mortality from 235 causes of 
death for 20 age groups in 1990 and 2010: a systematic analysis for the Global Burden of Disease Study 2010. Lancet 380(9859), 2095-2128 (2012)

2. S. Yusuf, S. Hawken, S. Ounpuu, T. Dans, A. Avezum, F. Lanas, M. McQueen, A. Budaj, P. Pais, J. Varigos, L. Lisheng, Effect of potentially modifiable risk factors associated with myocardial infarction in 52 countries (the INTERHEART study): case-control study. Lancet 364(9438), 937-952 (2004)

3. A.R. Cappola, P.W. Ladenson, Hypothyroidism and atherosclerosis. J. Clin. Endocrinol. Metab. 88(6), 2438-2444 (2003)

4. N. Rodondi, W.P. den Elzen, D.C. Bauer, A.R. Cappola, S. Razvi, J.P. Walsh, B.O. Asvold, G. Iervasi, M. Imaizumi, T.H. Collet, A. Bremner, P. Maisonneuve, J.A. Sgarbi, K.T. Khaw, M.P. Vanderpump, A.B. Newman, J. Cornuz, J.A. Franklyn, R.G. Westendorp, E. Vittinghoff, J. Gussekloo, Subclinical hypothyroidism and the risk of coronary heart disease and mortality. JAMA 304(12), 1365-1374 (2010)

5. S. Razvi, J.U. Weaver, T.J. Butler, S.H. Pearce, Levothyroxine treatment of subclinical hypothyroidism, fatal and nonfatal cardiovascular events, and mortality. Arch. Intern. Med. 172(10), 811-817 (2012)

6. M.I. Surks, J.G. Hollowell, Age-specific distribution of serum thyrotropin and antithyroid antibodies in the US population: implications for the prevalence of subclinical hypothyroidism. J. Clin. Endocrinol. Metab. 92(12), 4575-4582 (2007)

7. S. Taddei, N. Caraccio, A. Virdis, A. Dardano, D. Versari, L. Ghiadoni, E. Ferrannini, A. Salvetti, F. Monzani, Low-grade systemic inflammation causes endothelial dysfunction in patients with Hashimoto's thyroiditis. J. Clin. Endocrinol. Metab. 91(12), 5076-5082 (2006)

8. G. Mazziotti, F. Sorvillo, C. Naclerio, A. Farzati, M. Cioffi, R. Perna, G. Valentini, B. Farzati, G. Amato, C. Carella, Type-1 response in peripheral CD4+ and CD8+ T cells from patients with Hashimoto's thyroiditis. Eur. J. Endocrinol. 148(4), 383-388 (2003)
9. K.S. Stamatelopoulos, K. Kyrkou, E. Chrysochoou, H. Karga, S. Chatzidou, G. Georgiopoulos, S. Georgiou, K. Xiromeritis, C.M. Papamichael, M. Alevizaki, Arterial stiffness but not intimamedia thickness is increased in euthyroid patients with Hashimoto's thyroiditis: the effect of menopausal status. Thyroid 19(8), 857-862 (2009)

10. M.M. Ciccone, G. De Pergola, M.T. Porcelli, P. Scicchitano, P. Caldarola, M. Iacoviello, G. Pietro, F. Giorgino, S. Favale, Increased carotid IMT in overweight and obese women affected by Hashimoto's thyroiditis: an adiposity and autoimmune linkage? BMC Cardiovasc Disord 10, 22 (2010)

11. M.J. Nyirenda, D.N. Clark, A.R. Finlayson, J. Read, A. Elders, M. Bain, K.A. Fox, A.D. Toft, Thyroid disease and increased cardiovascular risk. Thyroid 15(7), 718-724 (2005)

12. B. Zoller, X. Li, J. Sundquist, K. Sundquist, Risk of subsequent coronary heart disease in patients hospitalized for immunemediated diseases: a nationwide follow-up study from Sweden. PLoS One 7(3), e33442 (2012)

13. B. Zoller, X. Li, J. Sundquist, K. Sundquist, Risk of subsequent ischemic and hemorrhagic stroke in patients hospitalized for immune-mediated diseases: a nationwide follow-up study from Sweden. BMC Neurol 12, 41 (2012)

14. O. Topaloglu, F. Gokay, K. Kucukler, F.S. Burnik, T. Mete, H.C. Yavuz, D. Berker, S. Guler, Is autoimmune thyroiditis a risk factor for early atherosclerosis in premenopausal women even if in euthyroid status? Endocrine (2012). doi:10.1007/s12020-012-9842-5

15. G. Tamer, M. Mert, I. Tamer, B. Mesci, D. Kilic, S. Arik, Effects of thyroid autoimmunity on abdominal obesity and hyperlipidaemia. Endokrynol Pol 62(5), 421-428 (2011)

16. P. Caturegli, A. De Remigis, M. Ferlito, M.A. Landek-Salgado, S. Iwama, S.C. Tzou, P.W. Ladenson, Anatabine ameliorates experimental autoimmune thyroiditis. Endocrinology 153(9), 4580-4587 (2012) 